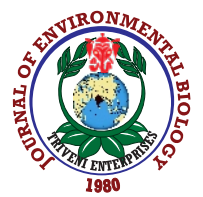

\title{
Antibiotic susceptibility of endosymbionts of papaya mealybug Paracoccus marginatus Williams and Granara de Willink (Hemiptera: Pseudococcidae)
}

\author{
P. Megaladevi and J. S. Kennedy* \\ Department of Agricultural Entomology, Tamil Nadu Agricultural University, Coimbatore-641 005, India \\ *Corresponding Author Email : jskennedy@tnau.ac.in
}

\section{Abstract}

Aim: The present study aimed to select a powerful tool to evaluate the antibiotic susceptibility of endosymbionts of papaya mealybug.

Methodology: Antibiotic Ofloxacin $(0.25 \mu \mathrm{g})$ was used to disrupt the endosymbionts of mealybug. The antibiotic susceptibility of endosymbionts was studied by conventional method; isolation of symbionts in Luria Bertani Agar and Nutrient Agar and also metagenomic analysis was conducted using nanopore sequencing of 16S rRNAgene.

Results: Molecular identification of isolates showed Grampositive bacteria i.e., Bacillus cluasii, B. altitudinis, B. siamensis and Gram-negative bacteria, i.e., Serratia marcescens and Stenotrophomonas maltophilia. Metagenomic analysis using $16 S$ amplicon sequencing resulted in identification of Candidatus Tremblaya Princeps (55\%) was more abundant followed by Candidatus Mikella endobia (23\%) in untreated mealybug population. Their population was reduced to $7 \%$ in Candidatus Tremblaya Princeps and below $1 \%$ in Candidatus Mikella endobia.

Interpretation: The current study confirms that the metagenomic analysis acts as a power lens to evaluate the antibiotic elimination of endosymbionts, hence with this method future works on developing aposymbiotic mealybugs can be done.

Key words: Endosymbiont, Metagenomic analysis, Ofloxacin, Papaya mealybug

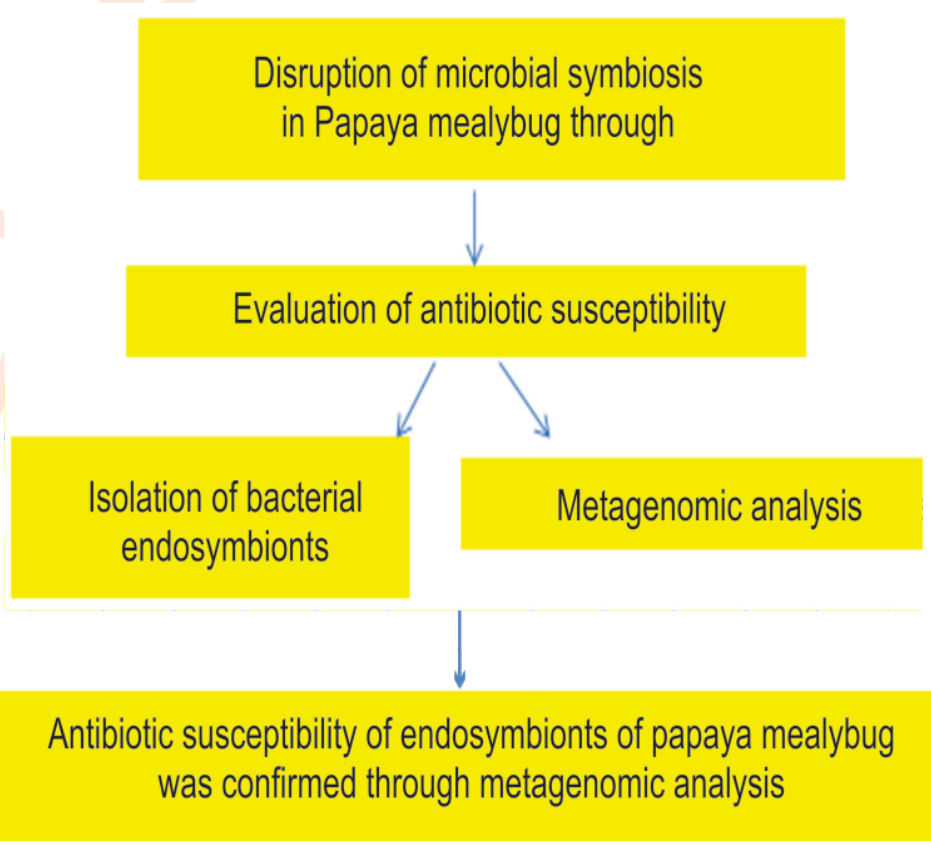

How to cite : Megaladevi, P. and J. S. Kennedy: Antibiotic susceptibility of endosymbionts of papaya mealybug Paracoccus marginatus Williams and Granara de Willink (Hemiptera: Pseudococcidae). J. Environ. Biol., 42, 1191-1194 (2021). 


\section{Introduction}

The papaya mealybug (PMB) Paracoccus marginatus Williams and Granara de Willink (Hemiptera: Pseudococcidae) was recorded for the first time in papaya during July 2008, in Coimbatore district Tamil Nadu. Severe infestation 80 to $90 \%$ was observed papaya, mulberry, tapioca, brinjal, tomato, bhendi and flower crops (Muniappan et al., 2008). Throughout their life, papaya mealybug, $P$. marginatus depends on endosymbiotic microorganisms for the supply of essential amino acids and other nutrients, whereby they can live solely on the specialized food source. In the current scenario, the disruption of microbial symbiosis demanded by insect pest and symbionts-mediated manipulation of insect pest traits are the two emerging trends in insect pest control.

Researchers have been unable to isolate the endosymbionts from insect body and culture the same in laboratory conditions. Unfortunately, traditional microbiology and microbial genome sequencing and genomics rely upon cultivated clonal cultures; early environmental gene sequencing cloned specific genes (often the $16 \mathrm{~S}$ rRNA gene) to produce a profile of microbial diversity in a natural sample. Hence, through traditional microbiological work, the vast majority of microbial biodiversity may miss from documenting. Metagenomics is the study of genetic material recovered directly from environmental samples and use either "shotgun" or PCR directed sequencing to get mostly unbiased samples of all genes from all the members of sampled communities. Because of its ability to reveal the previously hidden diversity of microscopic life, metagenomics offer a powerful lens for viewing the microbial world that has the potential to revolutionize understanding of the entire living world (Schloss and Handelsman, 2005). It appears that papaya mealybug houses number of secondary endosymbionts and many of them are not culturable in laboratory. These facultative secondary endosymbionts may play several roles in its host physiology viz., offers defense towards pathogens and parasites, influence insect- plant interaction, favours the host insect for adaptation to environment, impact on population dynamics and pesticide detoxification.

\section{Materials and Methods}

Isolation of culturable endosymbiotic bacteria from papaya mealybug: The culturable endosymbiotic bacteria of antibiotic treated (Ofloxacin @ 0.25 $\mathrm{gg}$ ) and untreated papaya mealybug from papaya host plant were isolated. Second and third instar nymphs (50 numbers) were taken and starved for 6-8 hr to eliminate the bacterial flora acquired through feeding the host plant. The starved nymphs were then surface sterilized with $70 \%$ ethanol followed by $0.1 \%$ sodium hypochlorite for $30 \mathrm{sec}$ to remove the adhering contaminants, especially external microflora. The remnants of disinfectants used for surface sterilization were then cleared by washing thoroughly with distilled water. After final wash, washed distilled water was plated on culture media to ensure complete elimination of external micro-flora. Surfacesterilized nymphs were homogenized using $1 \mathrm{ml}$ of $0.1 \mathrm{M}$ phosphate buffer in pestle and mortar.

The homogenates were serially diluted up to $10^{-3}$. A $100 \mu \mathrm{l}$ of each dilution of $10^{-1}, 10^{-2}$ and $10^{-3}$ were plated separately by pour plate method on two different sterile media such as Luria Bertani agar ( $10 \mathrm{~g}$ tryptone, $5 \mathrm{~g}$ yeast extract, $10 \mathrm{~g} \mathrm{NaCl}$ and $15 \mathrm{~g}$ agar) and Nutrient Agar ( $5 \mathrm{~g}$ peptone, $3 \mathrm{~g}$ beef extract, $5 \mathrm{~g} \mathrm{NaCl}$ and $20 \mathrm{~g}$ agar) and incubated at $28 \pm 2{ }^{\circ} \mathrm{C}$ for $24 \mathrm{~h}-72 \mathrm{~h}$ (de Vries and Visser, 2001). After incubation, the colonies grown on different media were selected on the basis of morphological characteristics such as shape, color and elevation. The selected colonies were subjected to sub-culturing on their respective medium for purification. Five to six subsequent streaking was done to obtain pure bacterial cultures. The purified cultures of endosymbiotic bacteria were maintained by sub-culturing on their respective medium for every 15 days. The purified cultures were examined under a light microscope and stored at $-80^{\circ} \mathrm{C}$ in $50 \%$ glycerol.

Molecular identification of bacterial isolates: The bacterial genomic DNA of bacterial cultures obtained from papaya mealybug was isolated using EXpure Microbial DNA isolation kit developed by Bogar Bio Bee stores Pvt. Ltd., India as per the protocol described in the instruction manual. The isolated DNA was then amplified through PCR (Polymerase Chain Reaction) targeting the 16 s ribosomal RNA (rRNA) gene using 27F (forward primer): 5'-AGAGTTTGATCCTGGCTCAG-3' and 1492R (reverse primer): 5'-GGTTACCTTGTTACGACTT- 3'. Removed unincorporated PCR primers and dNTPs from PCR products by using Montage PCR Clean up kit (Millipore). The PCR product was sequenced using primers. Sequencing reactions were performed using an ABI PRISM® BigDyeTM Terminator Cycle Sequencing Kits with AmpliTaq ${ }^{\circledR}$ DNA polymerase (FS enzyme) (Applied Bio-systems).

Metagenomic analysis of papaya mealybug: About $50,3^{\text {rd }}$ instar nymphs were taken from each PMB clone and used for metagenomic analysis. Genomic DNA was isolated from the surface sterilized mealybugs using c-TAB and phenol: chloroform extraction method. The isolated DNA was quantified using nanodrop by determining the $A 260 / 280$ ratio. The endosymbiotic profile of papaya mealybug were studied using Nanopore sequencing platform (Instrument make, Company, Location) with primers 27F 5' AGAGTTTGATCMTG and 1492R 5'AAGGAGGTGATCCAGCCGCA.

\section{Results and Discussion}

Molecular identification of isolates showed Grampositive bacteria, i.e., Bacillus cluasii, B. altitudinis, $B$. siamensis and Gram-negative bacteria, i.e., Serratia marcescens and Stenotrophomonas maltophilia (Table 1). Through conventional isolation and identification only few endosymbionts were isolated and cultured under laboratory conditions. It was not impossible to evaluate the antibiotic 
Table 1: Molecular characterization of culturable endosymbiotic bacteria isolated from papaya mealybug

\begin{tabular}{lllll}
\hline Isolates & Colony morphology & Gram test & Closest match & Genbank accession number \\
\hline TNAUPS1 & White, irregular & + & Bacillus altitudinis & Mn907690 \\
TNAUPS2 & Cream white, filamentous & + & Bacillus clausii & Mn907691 \\
TNAUPS3 & Creamy white, translucent & + & Bacillus siamensis & Mn907692 \\
TNAUPS4 & Red elevated, entire margin & - & Serratia marcescens & Mn907693 \\
TNAUPS5 & White convex, smooth & - & Stenotrophomonas maltophilia & Mn907694 \\
\hline
\end{tabular}
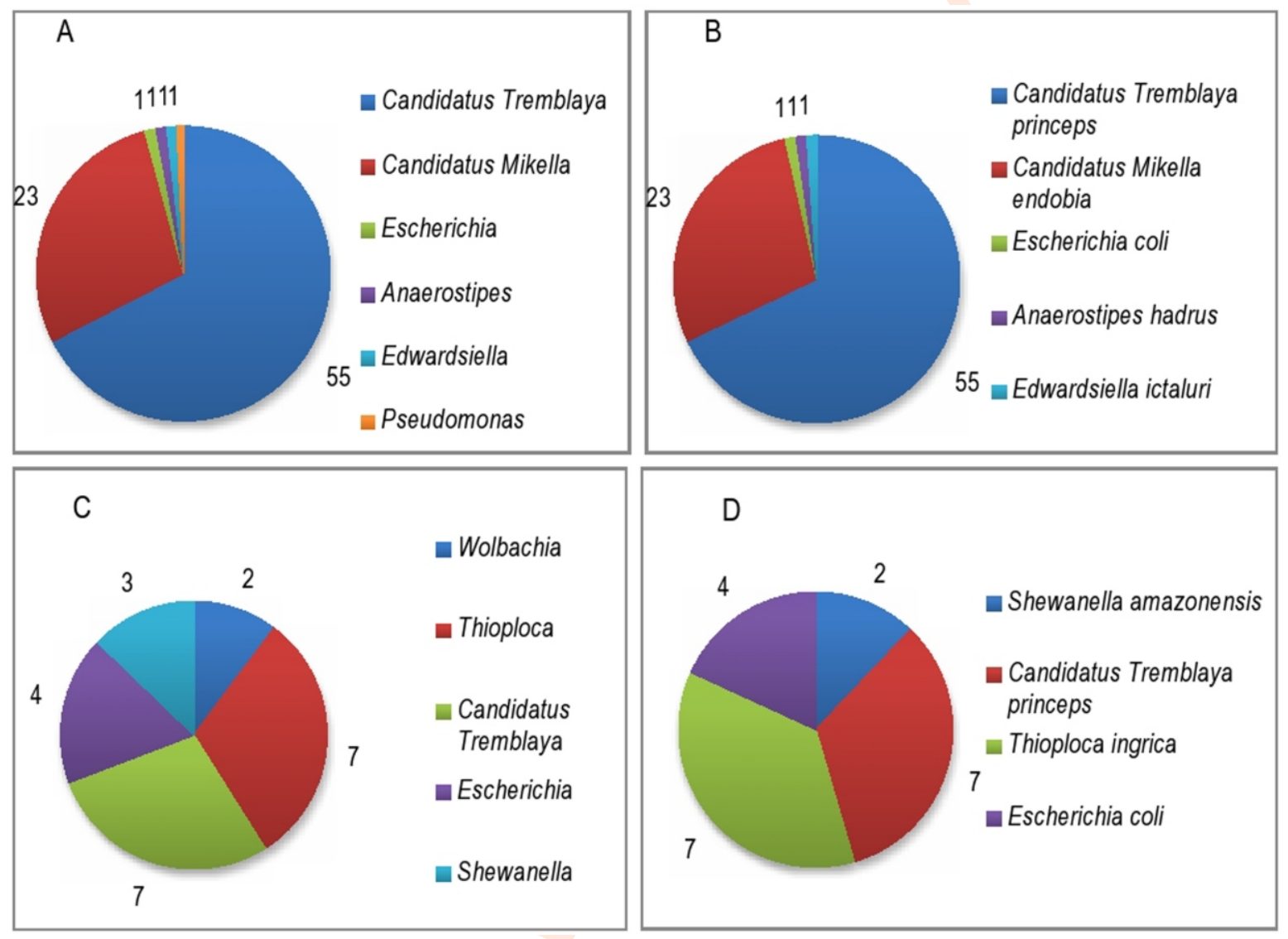

Fig. 1: Per cent abundance of bacterial endosymbionts from papaya mealybugs: (A) At genus level in control mealybug population; (B) At species level in control mealybug population; (C)At genus level in aposymbiotic mealybug population and (D)At species level in aposymbiotic mealybug population.

susceptibility as all the endosymbionts were not cultivable. As there are number uncultivable endosymbionts in insects, hence, metagenomic analysis was performed to explore the whole endosymbiotic profile of Papaya mealybug. Metagenomic analysis indicated that Candidatus Tremblaya Princeps (55\%) was more abundant followed by Candidatus Mikella endobia (23\%) in untreated population. Candidatus Tremblaya Princeps was reported as the primary endosymbiont of papaya mealybug and its presence is important for the survival and reproduction of its host insect. Their population reduced to $7 \%$ in Candidatus Tremblaya Princeps and below one per cent in Candidatus Mikella endobia.
This clearly confirms the influence of antibiotic ofloxacin on the abundance of endosymbionts of papaya mealybug (Fig. 1). While experimenting the isolation of bacterial endosymbiont associated with mealy bug, Rhizoecus amorphophalli (Hemiptera: Pseuococcidae), three culturable bacteria, namely, Bacillus subtilis, Staphylococcus gallinarum and $S$. saprophyticus were reported by Sreerag et al. (2014). Sreerag et al. (2014) reported three culturable bacteria, namely, Bacillus subtilis, Staphylococcus gallinarum and S. saprophyticus. The protective role of Serratia marcescens as an extracellular endosymbiont of Rhynchophorus ferrugineus was first reported by Scrascia et al. (2016). Stenotrophomonas sp. has been 
recognized to be associated with insects like Collembola. Indiragandhi et al. (2007) isolated Pseudomonas sp. and Stenotrophomonas sp. from the guts of larvae and adults of diamond back moth. Previous studies revealed that different lineages of mealybugs are associated with distinct lineages of bacterial endosymbionts. For example, many species of subfamily Pseudococcinae harbour a beta-proteobacterial endosymbiont Tremblaya princeps and an additional gammaproteobacterial endosymbiont (McCutcheon and Von Dohlen, 2011; Oliver, et al., 2005; Tamura et al., 2011; Thao, et al., 2002). The primary endosymbionts $T$. princeps are found in almost all Pseudococcine species and exhibit host-symbiont co-speciation (Muniappan et al., 2008; Von Dohlen, et al., 2001). In this study, metagenomics offers access to genetic diversity of uncultivable microbial communities. In future there is a need to explore their metabolic diversity.

In summary, metagenomic data have been useful in understanding the endosymbiotic profile in papaya mealybug with the establishment of both primary and secondary endosymbionts.

\section{Acknowledgments}

This study was conducted in partial requirement for $\mathrm{PhD}$ at the Tamil Nadu Agricultural University, Coimbatore. We duly Yaazh Xenomics, Coimbatore for assistance in the metagenomic analysis.

\section{Add-on Information}

Authors' contribution: P. Megaladevi: Sample collection, DNA extraction, Molecular Biology, Bioinformatics, Data interpretation, and Manuscript writing; J.S. Kennedy: Conceptualization of study, Bioinformatics, Data interpretation, and Manuscript writing.

Research content: The research content of manuscript is original and has not been published elsewhere.

\section{Ethical approval: NotApplicable}

Conflict of interest: The authors declare that there is no conflict of interest.

Data from other sources: NotApplicable
Consent to publish: All authors agree to publish the paper in Journal of Environmental Biology.

\section{References}

de Vries, R.P. and J. Visser: Aspergillus enzymes involved in degradation of plant cell wall polysaccharides. Microbiol. Mol. Biol. Rev., 65, 497-522 (2001).

Indiragandhi, P., R. Anandham, M. Madhaiyan, S. Poonguzhali, G.H. $\mathrm{Kim}$, V.S. Saravanan and T. Sa: Cultivable bacteria associated with larval gut of prothiofos-resistant, prothiofos-susceptible and field-caught populations of diamondback moth, Plutella xylostella and their potential for, antagonism towards entomopathogenic fungi and host insect nutrition. J. Appli. Microbiol., 103, 2664-2675 (2007).

Mc Cutcheon, J.P. and C.D. Von Dohlen: An interdependent metabolic patchwork in the nested symbiosis of mealybugs. Curr. Biol., 21, 1366-1372 (2011).

Muniappan, R., B.M. Shepard, G.W. Watson, G.R. Carner, D. Sartiami, A. Rauf and M.D. Hammig: First report of the papaya mealybug, Paracoccus marginatus (Hemiptera: Pseudococcidae), in Indonesia and India. J. Agricul. Urban Entomol., 25, 37-40 (2008).

Oliver, K.M., N.A. Moran and M.S. Hunter: Variation in resistance to parasitism in aphids is due to symbionts not host genotype. Proc. Nati.Acad. Sci., 102, 12795-12800 (2005).

Schloss, P.D. and J. Handelsman: Metagenomics for studying unculturable microorganisms: Cutting the Gordian knot. Genome Biol., 6, 229 (2005).

Scrascia, M., C. Pazzani, F. Valentini, M. Oliva, V. Russo, P. D'Addabbo, and F. Porcelli: Identification of pigmented Serratia marcescens symbiotically associated with Rhynchophorus ferrugineus Olivier (Coleoptera: Curculionidae). Microbiology Open, 5, 883-890 (2016).

Sreerag, R.S., C.A. Jayaprakas, L. Ragesh and S.N. Kumar: Endosymbiotic bacteria associated with the mealy bug, Rhizoecus amorphophalli (Hemiptera: Pseudococcidae). Int. Sch. Res. Notices, 268491 (2014).

Tamura, K., D. Peterson, N. Peterson, G. Stecher, M. Nei and S. Kumar: MEGA5: Molecular evolutionary genetics analysis using maximum likelihood, evolutionary distance, and maximum parsimony methods. Mole. Biol. Evol., 28, 2731-2739 (2011).

Thao, M.L., P.J. Gullan and P. Baumann: Secondary (y-Proteobacteria) endosymbionts infect the primary ( $\beta$-Proteobacteria) endosymbionts of mealybugs multiple times and coevolve with their hosts. Appl. Environ. Microbiol., 68, 3190-3197 (2002).

Von Dohlen, C.D., S. Kohler, S.T. Alsop and W.R. McManus: Mealybug $\beta-$ proteobacterial endosymbionts contain $\mathrm{Y}$-proteobacterial symbionts. Nature, 412, 433-436 (2001). 